\title{
Э. Пинелли
}

Павийский университет, 27100 г. Павия, Италия

\section{Санкции против России: представление первой фазы санкционного процесса в российских СМИ}

В статье рассматривается представление российскими СМИ начальной фазы санкционной политики против России (февраль-август 2014 г.). Исследование основывается на данных Национального корпуса русского языка (Газетного подкорпуса) и проводится с помощью анализа конкордансов слова санкции. Анализ самых частотных и значимых языковых элементов позволяет описать представление санкций, в том числе метафорическое, в российском медийном дискурсе.

Ключевые слова: санкции, русский язык, медийный дискурс, конкордансы, метафора

ДЛЯ ЦИТИРОВАНИЯ: Пинелли Э. Санкции против России: представление первой фазы санкционного процесса в российских СМИ // Рема. Rhema. 2019. № 4. C. 70-85. DOI: 10.31862/2500-2953-2019-4-70-85 


\section{E. Pinelli}

University of Pavia,

Pavia, 27100, Italy

\section{Sanctions against Russia: Presentation of the first period of the sanctioning process in Russian media}

In this paper I analyze how sanctions against Russia are framed in Russian newspapers in the first period after the Ukrainian crisis. The analysis is based on data from the Newspaper subcorpus of the Russian National Corpus, which contains newspaper articles published from February to August 2014. Through concordance analysis of the word sankcii 'sanctions', we analyze the representation, also metaphorical, of sanctions in Russian media discourse.

Key words: sanctions, Russian, media discourse, concordances, metaphor

FOR CITATION: Pinelli E. Sanctions against Russia: Presentation of the first period of the sanctioning process in Russian media. Rhema. 2019. No. 4. Pp. 70-85. (In Russ.) DOI: 10.31862/2500-2953-2019-4-70-85

\section{1. Введение}

В ответ украинскому кризису в 2014 г. США вместе с Евросоюзом и другими западными странами решили ввести ряд санкций против России. Первые санкции, главным образом против российских физических лиц, были введены в марте, а основные меры против российских организаций были приняты в сентябре 2014 г.

В данной статье рассматривается изображение первой фазы санкционной политики в российских СМИ, т.е. в статьях, опубликованных с февраля по август 2014 г. В частности, в статье анализируются разные языковые элементы, играющие роль в создании образа санкционного процесса и задействованных в нем лиц. 
Статья организована следующим образом. Во втором разделе обсуждается метод конкордансов для анализа контекстов ключевых слов в дискурсе. В третьем разделе рассматривается роль метафоры в дискурсе, в частности - медийном. В четвертом разделе после описания использованных данных и методологии представлены результаты количественного и качественного анализа конкордансов. Проведенный анализ включает в себя исследование семантики прилагательных (раздел 4.1) и глаголов (раздел 4.2), встречающихся в контексте слова санкции, а также метафорического представления первой фазы санкционного процесса в российских СМИ (разделы 4.2.1 и 4.2.2). Пятый раздел представляет собой обобщение полученных результатов.

\section{2. Конкордансы и анализ дискурса}

Анализ дискурса осуществляется различными методами исследования, включая методы когнитивной и корпусной лингвистики.

Н. Фэйрклаф определяет дискурс как вид социальной практики [Fairclough, 1989, p. 22-23], подразумевая, что лингвистические феномены, в том числе и дискурс, имеют социальные последствия. Многочисленные исследования показывают, что использование различных языковых элементов в дискурсе может влиять на понимание реальности и даже создавать определенное представление о событиях.

Со второй половины XX в. лингвисты стали обращать особое внимание на семантику слов. Некоторые ученые заметили, что слово устанавливает значительные связи с другими словами в контексте. Следовательно, из контекста можно многое узнать о значении слова и о концепте, выраженным этим словом [Sinclair, 1991, 2004; Baker, 2006 и др.].

Основываясь на большом количестве реальных языковых реализаций, т.е. на корпусах, корпусная лингвистика предоставляет инструменты для анализа семантики слов в контексте. Как отмечает П. Бейкер, методы корпусной лингвистики позволяют уменьшить субъективность в отборе и анализе языковых данных благодаря тому, что исследователь может опираться не только на качественный анализ, но и на выявление количественной (и статистической) значимости определенного языкового элемента [Baker, 2006, p. 10-12]. Основным методом анализа семантики слов в дискурсе является исследование конкордансов, т.е. ключевых слов в контексте [Sinclair, 1991, p. 32]. Анализ конкордансов и комбинация качественных и количественных методов позволяют провести глубокий анализ языковых данных [Baker, 2006, p. 71].

Обсуждая роль власти в дискурсе СМИ, Н. Фэйрклаф отмечает, что, хотя сам по себе текст незначим, с помощью повторения определенного воссоздания событий, массмедийный дискурс может повлиять 
на представление реальности [Fairclough, 1989, p. 54]. Когнитивные исследования также подтвердили, что слова связаны с глубокими ментальными структурами - фреймами, благодаря которым человек понимает окружающий мир [Lakoff, 2006]. Фреймы структурируют наши идеи и могут направлять наши реакции. Повторение слова, связанного с определенным фреймом, закрепляет этот фрейм и, следовательно, связанную с ним идею [Lakoff, 2004, 2006]. Таким образом, количественный анализ является важным для выявления ключевых понятий в дискурсе.

\section{3. Роль метафоры в медийном дискурсе}

Когнитивная лингвистика предоставляет в распоряжение исследователей дополнительные инструменты для лингвистического анализа, в том числе и для анализа дискурса. Одним из базовых понятий в когнитивной лингвистике является понятие метафоры. В когнитивной лингвистике метафора рассматривается не как речевое средство украшения дискурса, а как когнитивный процесс представления одного концепта через другой. Метафора, проецирующая один сложный и абстрактный концептуальный домен ${ }^{1}$ на более простой и конкретный домен, позволяет нам понимать и категоризировать окружающий мир [Lakoff, Johnson, 1980; Kövecses, 2010 и др.].

Как было показано рядом исследователей, метафоры играют важную роль в дискурсе, в том числе в политическом и массмедийном [Баранов, 2001; Lakoff, 2004; Charteris-Black, 2004; Чудинов, 2006 и др.], и могут способствовать определенному представлению событий. Это связано с тем, что описание событий с помощью метафор неизбежно упрощает понимание реальности; в действительности при употреблении метафор некоторые избранные автором аспекты подчеркиваются, а другие скрываются.

Что касается дискурса о санкциях, некоторые ученые в своих работах [Кропотухина, Тихонов, 2015; Ковязина, Ильющеня, Хабибуллина, 2018; Абрамова, Субботина, Климова, 2019] отмечают, что военная метафора - одна из важнейших метафор, как в западных, так и в российских газетах. Многочисленные исследования показывают, что метафора войны является средством описания политических или экономических отношений в политическом дискурсе и в СМИ в общем [Чудинов, 2006; Будаев, 2008 и др.]. В частности, обсуждая дискурс в российских газетах,

\footnotetext{
${ }^{1}$ В когнитивной лингвистике «домен» - это структурированное пространство фоновых знаний, которые основываются на опыте непосредственного взаимодействия человека с окружающим миром. У. Крофт и Д.А. Круз определяют домен как «семантическую структуру, которая служит в качестве основы для профилирования хотя бы одного концепта» [Croft, Cruse, 2004, p. 15].
} 
Е.С. Абрамова, И.М. Субботина и Ю.А. Климова утверждают, что метафора войны используется наряду с метафорами ТЕАТРА и игРЫ, чтобы создать образ Запада [Абрамова, Субботина, Климова, 2019, с. 170].

В санкционном дискурсе также встречается метафора БолЕзни. П.В. Кропотухина и В.В. Тихонов показывают, что в западных СМИ метафора БолЕзни используется, чтобы представить европейской и американской публике страдающую от санкций Россию; напротив, в российских СМИ с помощью этой метафоры санкции представляются как «излечимая болезнь» [Кропотухина, Тихонов, 2015, с. 98]. Как мы покажем ниже (раздел 4.2.1), метафоры войны и БолЕзни взаимодействуют в дискурсе о санкциях в российских СМИ, создают вместе с другими метафорами и языковыми элементами определенное изображение событий и повышают эмоциональную нагрузку дискурса.

\section{4. Данные и методология}

В данной статье анализируется представление первой фазы санкций против России со стороны западных стран в российских СМИ. Материалом исследования послужили данные, извлеченные из Газетного подкорпуса Национального корпуса русского языка (НКРЯ, www.ruscorpora.ru). Использованный для анализа корпус включает в себя статьи, опубликованные в российских газетах и на сайтах информационных агентств («Известия», «Комсомольская правда», «РБК daily», РИА Новости, ИА Прайм) с февраля по август 2014 г.

По данным словаря, слово санкиия в интересующем нас значении встречается преимущественно во множественном числе и определяется следующим образом: «в международном праве - мероприятия, репрессии против стороны, нарушающей свои обязательства, договоры» [Ушаков, 2008, с. 960]. Следует отметить, что употребление этого слова предусматривает пресуппозицию, что кто-то нарушил договоры. Слово санкции, хотя и отражает западный взгляд на события, встречается как в западных, так и в российских газетах.

Настоящее исследование основывается на анализе конкордансов слова санкция, встречающегося во множественном числе. Опираясь на результаты анализа конкордансов, мы рассмотрим некоторые языковые элементы, создающие определенное представление реальности, в том числе и метафоры.

В целом были анализированы 2572 вхождения слова санкции. Для анализа языковых данных была использована в основном поисковая система НКРЯ. Для построения конкордансов в более удобном для анализа виде данные были внесены в программу AntConc. 


\section{1. Определение санкций в дискурсе}

Одним из элементов, играющих ключевую роль в создании образа санкций, является употребление прилагательных. В табл. 1 приводятся результаты анализа.

\section{Таблийа 1}

\section{Прилагательные, относящиеся к слову санкции}

\begin{tabular}{|c|c|c|c|}
\hline Определение & Количество & Определение & Количество \\
\hline Экономические & 136 & Мягкие & 6 \\
\hline Hoвble & 78 & Очередные & 6 \\
\hline Возможные & 67 & Аналогичные & 5 \\
\hline Штрафныее & 45 & Индивидуальные & 5 \\
\hline Жесткие & 41 & Секторальные & 5 \\
\hline Американские & 40 & Адресные & 4 \\
\hline Западные & 26 & Денежные & 4 \\
\hline Международнье & 25 & Другие & 4 \\
\hline Серьезные & 25 & Иностранные & 4 \\
\hline Антироссийские & 14 & Налоговые & 4 \\
\hline Oтветные & 14 & Потенциальные & 4 \\
\hline Tорговые & 14 & Уголовные & 4 \\
\hline Финансовые & 14 & «Крылмские» & 3 \\
\hline Персональные & 13 & Данныле & 3 \\
\hline Дальнейшие & 12 & Иньее & 3 \\
\hline Дополнительные & 12 & Отраслевые & 3 \\
\hline Подобные & 10 & Повыменные & 3 \\
\hline Политические & 10 & «Украинские» & 2 \\
\hline Визовые & 8 & Болезненные & 2 \\
\hline Односторонние & 7 & Высокие & 2 \\
\hline Точечные & 7 & Дипломатические & 2 \\
\hline Европейские & 6 & Зеркальные & 2 \\
\hline
\end{tabular}


Окончание табл. 1

\begin{tabular}{|c|c|c|c|}
\hline Определение & Количество & Определение & Количество \\
\hline Канадские & 2 & Газовые & 1 \\
\hline Конкретные & 2 & Гласные & 1 \\
\hline Негласные & 2 & Глобальные & 1 \\
\hline Ограничительные & 2 & Нелепье & 1 \\
\hline Основные & 2 & Несправедливые & 1 \\
\hline Отдельные & 2 & Неформальные & 1 \\
\hline Официальньее & 2 & Определенные & 1 \\
\hline Реальные & 2 & Последуюшче & 1 \\
\hline Строгие & 2 & Профилактические & 1 \\
\hline Технологические & 2 & Публичные & 1 \\
\hline Юридические & 2 & Различные & 1 \\
\hline Японские & 2 & Разнообразные & 1 \\
\hline Альтернативные & 1 & Разрушительные & 1 \\
\hline Будущчие & 1 & Тяжелье & 1 \\
\hline Бысттрые & 1 & Ясныле & 1 \\
\hline Выборочные & 1 & & \\
\hline
\end{tabular}

* Прилагательное uтрафные не является показательным, т.к. словосочетание uтрафные санкции часто означает различные административные меры.

Как видно из табл. 1, самое частотное прилагательное экономические (136 вхождений) определяет вид санкций и уточняет сферу их действия, как и прилагательные торговые, финансовые, визовые, индивидуальные, секторальные и т.д. Другие прилагательные, как например: новые, возможные, очередные и дальнейшие, подчеркивают, что санкционная политика еще действует и поэтому ожидаются новые санкции. Прилагательные американские (40 вхождений) и европейские (6 вхождений) указывают на инициаторов санкционного процесса. Из табл. 1 видно, что США являются главными инициаторами санкций, а Европа, особенно в первой фазе, не играет главной роли в этом процессе. Интересно отметить, что в корпусе присутствует более общий и неопределенный агенс - другие страны или Запад. Он упоминается с помощью 
прилагательных западные (26 вхождений), международные (25 вхождений) и глобальные (1 вхождение). Кроме того, прилагательное антироссийский указывает на пострадавшего и одновременно уточняет роль России как противника Запада. Прилагательное ответные (14 вхождений, см. раздел 4.2.2) выражает реакцию на действия инициатора. Встречающиеся реже прилагательные «украинские» и «крылмские» помогают описывать события, указывая на причину санкций.

Другие прилагательные определяют санкции как жесткие (41 вхождение), серьезные (25 вхождений) и тяжелье (1 вхождение), в то же время употребление прилагательного мягкие (6 вхождений) указывает на неэффективность санкционного процесса (см. раздел 4.2.). Кроме того, редкие, но обладающие важной смысловой нагрузкой прилагательные, как, например, несправедливые и нелепые, отрицательно коннотируют санкционную политику. Интересно отметить, что некоторые прилагательные связаны с понятием болезни: прилагательное болезненные отсылает к возможному страданию (не только России, см. раздел 4.2.1) из-за санкций, а профилактические отражает взгляд западных стран и встречается в дискурсах представителей стран-инициаторов.

\section{2. Первые западные санкции против России: кто действует и как?}

В этом разделе статьи анализируется семантика глагольных форм, встречающихся в контексте слова санкици ${ }^{2}$. Самые частотные и интересные результаты обобщены в табл. 2.

Самые частотные глаголы, такие как вводить/ввести (300 вхождений), применять/применить (58 вхождений), накладывать/наложить (41 вхождение), указывают на начало санкционного процесса. Другие довольно частотные глаголы, как, например, опасаться (18 вхождений) и бояться (16 вхождений), ассоциируются с отрицательной эмоцией страха. Следует отметить, что эти глаголы, прежде всего, встречаются при отрицании, чтобы подчеркнуть неэффективность санкций против России:

(1) Ответной реакции в виде санкичй Кремль не боится, считая, что ущзерб будет взаимнылм. (РБК daily, 2014.03.05)

Даже при отрицании употребление глаголов бояться и опасаться позволяет ассоциировать санкции со страхом и усиливает эмоциональную

\footnotetext{
2 При проведении анализа учитывались глаголы, встречающиеся в контекстном окне 5 слов слева и 5 слов справа от ключевого слова санкции. Результаты были проверены вручную.
} 
нагрузку дискурса. В других случаях эти глаголы выражают нерешительное поведение Запада, в частности Европы.

(2) Вся Eвропа сейчас опасается вводить действенные экономические санкиии... (РБК daily, 2014.06.24)

Другие частотные глаголы, как, например, угрожать, страдать и попасть, являются особенно интересными для анализа и обсуждаются отдельно (разделы 4.2.1 и 4.2.2).

Таблицуа 2

\section{Глаголы, встречающиеся в контексте слова санкции}

\begin{tabular}{|c|c|c|c|}
\hline Глаголы & Количество & Глаголы & Количество \\
\hline Ввести/вводить (ся) & 300 & $\begin{array}{l}\text { Распространять }(с я) / \\
\text { распространить }(с я)\end{array}$ & 16 \\
\hline Попадать/nonacmb & 80 & Действовать & 16 \\
\hline Применять/применить & 58 & Назвать/называть & 15 \\
\hline $\begin{array}{l}\text { Накладьлвать/ } \\
\text { наложить }\end{array}$ & 41 & Угрожать & 14 \\
\hline Подпадать/nодпасmь & 38 & $\begin{array}{l}\text { Ограничивать/ } \\
\text { ограничить (ся) }\end{array}$ & 13 \\
\hline Становиться/стать & 38 & $\begin{array}{l}\text { Подвергать (ся)/ } \\
\text { подвергнуть(ся) }\end{array}$ & 11 \\
\hline Объявить/объявлять & 35 & Расширять/расширить & 11 \\
\hline Коснуться & 29 & Ужесточить & 9 \\
\hline Грозить & 24 & Ждать & 9 \\
\hline $\begin{array}{l}\text { Обсуждать (ся)/ } \\
\text { обсудить }\end{array}$ & 23 & Пригрозить & 6 \\
\hline Cтрадать/nострадать & 21 & Означать & 6 \\
\hline Оказывать/оказать (ся) & 21 & Избежать & 5 \\
\hline $\begin{array}{l}\text { Поддержать/ } \\
\text { поддерживать }\end{array}$ & 20 & Запугивать/запугать & 2 \\
\hline Onacambcя & 18 & Нарушить & 2 \\
\hline Бояться & 16 & Шантажировать & 2 \\
\hline
\end{tabular}




\subsection{1. Угроза санкций - начало конфликта}

Как уже было отмечено в разделе 4.2, некоторые частотные глаголы в дискурсе о санкциях ассоциируются с чувством страха и с тесно связанным с ним понятием угрозы. В дискурсе слово санкции часто встречается с глаголами, выражающими угрозу, как например: угрожать (14 вхождений), грозить (24 вхождения), пригрозить (6 вхождений) и редкий, но с важной смысловой нагрузкой глагол шантажировать (2 вхождения) (табл. 2).

Такие понятия, как «угроза», «агрессия» и «давление», обозначают первую фазу войны [Абрамова, Субботина, Климова, 2019, с. 168]. Следовательно, присутствие этих понятий в дискурсе показывает, что первая фаза санкционного процесса метафорически представляется как начало конфликта между двумя сторонами, в частности между Россией и Западом («санкции - это война»; см. разд. 3). Интересно отметить, что анализ контекстов, в которых встречаются глаголы угрозы, показал, что слово санкциии чаще всего играет роль инструмента.

(3) Запад угрожает Москве санкциями и отзывает собственных дипломатов... (Известия, 2014.03.03)

В примере (3) видно, что слово санкиии в творительном падеже понимается не только как инструмент, но при употреблении с глаголом угрожать получает метафорическую интерпретацию как орудия. Кроме того, в дискурсе о санкциях встречаются также более очевидные метафорические выражения:

(4) Власти США могут расчехлить грозное «холодное» оружие применить санкции в отношении ряда российских банков по иранскому образиу. (РБК daily, 2014.03.06)

В примере (4) с помощью слов оружие и расчехлить процесс введения санкций представляется выстрелом. Следует также отметить, что метафорическое выражение холодное оружие непосредственно связывается с понятием холодной войны.

В российских СМИ, как и в некоторых западных, санкции сравниваются с бумерангом - оружием, которое может навредить не только тому, на кого направлена «атака», но и тому, кто совершает это действие, т.е. Западу.

(5) Европе, учитывая тесные связи многих стран - членов союза с Россией, прийти к единому мнению гораздо труднее. В первую очередь санкции против Москвы могут бумерангом ударить по Италии, Греции, Германии, Кипру и Австрии.

(РБК daily, 2014.05.26) 
В примере (5) метафора бумеранга употребляется также при описания нерешительного поведения Евросоюза касательно введения санкций против России из-за их возможных последствий на экономику европейских стран. Эта метафора позволяет представить отрицательный образ разобщенной Европы и показывает сильную сторону России. Влияние санкций на экономику инициатора выражается также метафорическим выражением «санкции - это обоюдоострое оружие»:

(6) Санкции - оружие обоюдоострое: в сегодняшнем финансовом мире все взаимосвязано. От них пострадает не только Россия, но и те самые страны, которые стали их инициаторами (Известия, 2014.03.21)

Метафора «санкции - это оружие» часто употребляется вместе с метафорой ьолЕзни. Такие слова, как, например, пострадать (пример 6) и болезненный (пример 7), подчеркивают, что санкции, как оружие, могут оказаться опасными и принести страдания.

(7) Серьезные санкции окажутся взаимно болезненными. (Известия, 2014.04.02)

Метафоры войны и БолЕзни безусловно дополняют друг друга, усиливая эмоциональное воздействие и создавая не только образ пострадавшей России, но и образ пострадавших и угрожающих стран-инициаторов (примеры 6 и 7). Представление санкций как оружия связано с понятием давления:

(8) Разве не очевидно, что экономические санкции как инструмент политического давления имеют вид бумеранга и в конечном счете влияют на тех, кто их запустил? - заявил президент. (Известия, 2014.05.23)

Наряду с метафорой войны понятие давления описывает положение России, находящей под внешней угрозой. Кроме того, в рассматриваемых текстах очень часто говорится о неэффективности американских и европейских санкций.

(9) По оценкам экспертов Минэнерго, в ближайшие три года серьезного влияния введение технологических санкций не окажет. (РБК Дейли, 2014.05.14)

Как показывает пример (9), слово санкиии часто встречается в предложениях с отрицанием, чтобы подчеркнуть незначительную эффективность санкций. Кроме того, употребление этих слов и метафор, несмотря на отрицание, помогает создать определенную ситуацию в дискурсе: Россия - сильная страна, но она находится под угрозой. 
Понятия давления и угрозы усиливаются в дискурсе с помощью других языковых элементов. Хотя высокочастотность предлогов в дискурсе может быть незначительной, анализ конкордансов показывает, что санкиии против России является один из самых частотных кластеров (149 вхождений) (рис. 1). Интересно отметить, что, хотя в первой фазе санкции коснулись только отдельных физических лиц и компаний, в анализируемом нами дискурсе под угрозой представляется вся Россия. В контексте слова санкиии встречаются также такие словосочетания, как против РФ (15 вхождений), против Москвы (12 вхождений), и такие, более нейтральные формы, как в отношении России (66 вхождений) и в отношении Москвы (9 вхождений).

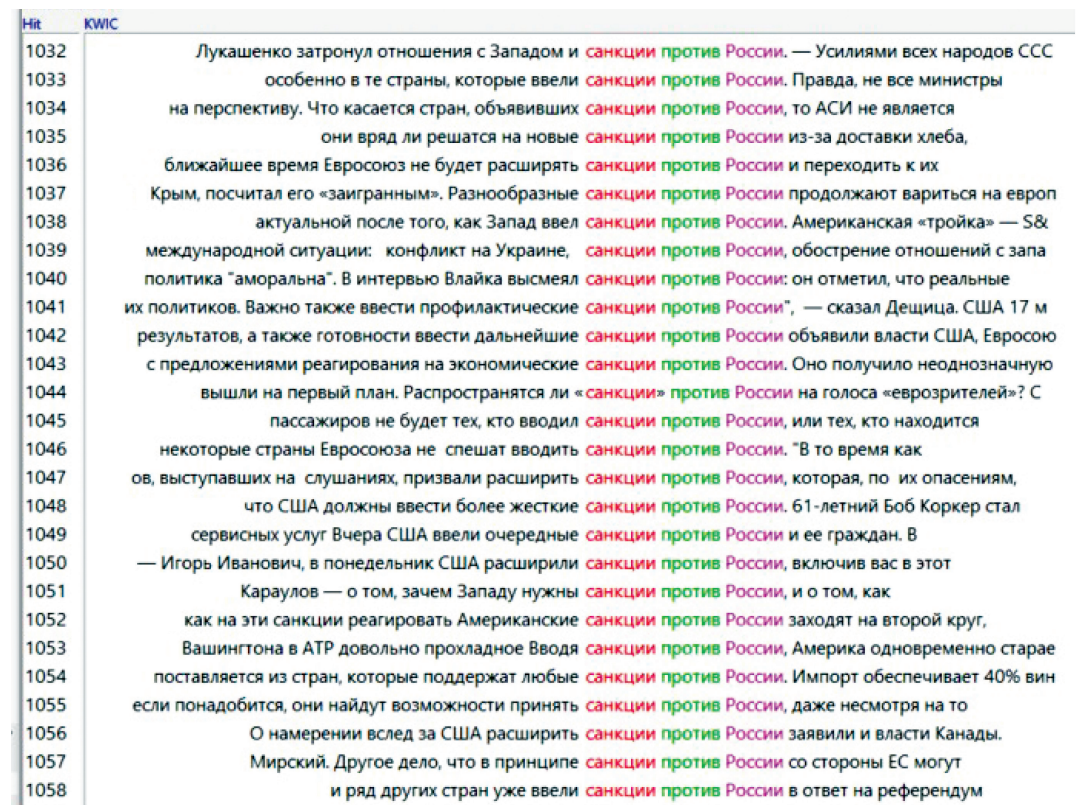

Рис. 1. Конкордансы слова санкции в программе AntConc (санкции против России)

Высокочастотность предлога против не вызывает удивления, если учесть, что слово санкиии обозначает, что против кого-то принимают меры. Другим частотным предлогом является предлог под (под + caнкции, 118 вхождений).

Поскольку важным компонентом семантики предлога под является «функциональная доминация» [Плунгян, Рахилина, 2000, с. 123], 
употребление этого предлога в дискурсе может усилить образ санкций как средства давления. Частотными кластерами в корпусе являются попасть под санкции (61 вхождение) (рис. 2) и подпасть под санкции (22 вхождения); в этих конструкциях понятие доминации, выражаемое предлогом под, соединяется с отрицательной коннотацией глаголов nопасть и подnacmb, вызванной ориентированной метафорой плохоЕ это внизу [Lakoff, Johnson, 1980, p. 17]. Стоит отметить, что в этих более специфических конструкциях никогда не упоминается Россия, а лишь те физические лица и компании, на которых направлены санкции.

\begin{tabular}{|c|c|}
\hline Hit & KMC \\
\hline 862 & в этот список. «Повторное попадание под санкции уже в качестве самостоятельного юридическо \\
\hline 863 & зали список российских чиновников, попадающих под санкции. В нем, в частности, оказались министр \\
\hline 864 & терминалом Qіwi, эта сеть попадет под санкции Управляющая платежной системой Qіwi одноим \\
\hline 865 & контора через неделю закроется, попадет под санкции по Крыму, что является неправдой и \\
\hline 866 & держателем акций змитента, который попал под санкциии, эти бумаги могут быть немедленно замороже \\
\hline 867 & «Россия» в конце марта попал под санкции США, Юрию Ковальчуку, давнему знакомому \\
\hline 868 & " Сергей Миронов, который также попал под санкции Европы и Америки, заявил о своем \\
\hline 869 & введения санкций (Олег Пантелеев попал под санкции ЕС и США. — «Известия») для меня \\
\hline 870 & Владимир Якунин, который также попал под санкции США, летом также предпочтет отдых в \\
\hline 871 & и прокурорские работники. Муров попал под санкции США 29 апреля: его фамилии в первом ж \\
\hline 872 & Бизнесмен Геннадий Тимченко, который попал под санкции США и распродал большинство зарубежных акт \\
\hline 873 & пойдут, а те, кто попая под санкции, как банк «Россия», будут работать, так \\
\hline 874 & и тем более банк попал под санкции, - такую возможность можно рассмотреть. \\
\hline 875 & јещено пересылать отправления. Чиновник попал под санкции США, Канады и Евросоюза, объяснил РБК \\
\hline 876 & со мной. Господин Киселев попал под санкции по решению Совета Евросоюза, нацеленного н \\
\hline 877 & ситуацией на Украине она попала под санкции, однако не европейские, а американские. Зд \\
\hline 878 & 4.04.17] [Алена Сивкова. Мизулина: «Я попала под санкции США из-за местиж // Известия, 2014.03.18] \\
\hline 879 & и вице-премьерами, которые попали под санкции «в связи с известными событиямиж, - Речь \\
\hline 880 & президента Виктор Медведчук, которые попали под санкции Канады. США 17 марта решили ввести санкции \\
\hline 881 & состоится. - За что вы попали под санкции Запада? Мешают ли они вам как \\
\hline 882 & российских банков по активам, попали под санкции впервые. Оба банка в тот же \\
\hline 883 & Сбербанк, ни УЭК не попали под санкции США, в отличие отряда российских банков, \\
\hline 884 & что хочется, коли уж попали под санкциив, — объясняет логику администрации Обамы \\
\hline 885 & президента Виктор Медведчук, которые попали под санкции Канады в связи с ситуацией на \\
\hline 886 & поинтересовались, почему эти лица попали под санкции - из-за дружбы с ним или \\
\hline 887 & итное учреждение, которое незаслуженно попало под санкции Запада. - Следую за главой Чеченской Респу \\
\hline 888 & Крыму из-за боязни попасть под санкции. - Те люди, которые посещают Крым, могут \\
\hline 889 & которые посещают Крым, могут попасть под санкции. Если речь идет о менеджменте «Газпрома», \\
\hline 890 & организации, действующие там, рискуют попасть под санкции со стороны Украины и международного сообще \\
\hline 891 & они остаются в тени) попасть под санкции контролирующих служб, говорит Карен Вартап \\
\hline 892 & президент все-таки может попасть под санкции, полагают некоторые аналитики. Любое обост \\
\hline
\end{tabular}

Рис. 2. Конкордансы слова санкции в программе AntConc (nonacmb nод санкциu)

\subsection{2. Представление реакции России на западные санкции}

Как было показано в разделе 4.2.1, в дискурсе российских СМИ санкции США и Европы представляются главным образом как конфликт. В этом разделе обсуждается представление реакции России на угрозу 
России, вопрос санкций и отношений с Западом не выражается метафорой конфликта, а доминирует компонент сотрудничества в коммуникации. Словосочетание ответные санкиии встречается 16 раз (табл. 1). Хотя прилагательное ответный обозначает реакции, вызванные какимто вопросом или действием, оно относится преимущественно к сфере общения и коммуникации. В корпусе встречаются также и более нейтральные формы, как например: ответные меры (17 вхождений), ответные реакции (6 вхождений), ответные шаги (2 вхождения). Следует отметить, что метафора общения употребляется, чтобы подчеркнуть разницу между действием Запада и реакцией России.

(10) Будем считать, что США чисто эстетически понравилась идея «говорить языком санкций», как это называет наш МИД, причем именно с великой Россией, страной Толстого и Достоевского. Или, выражаясь точнее, «ботать по фене санкций» <... >. Нам же важно найти правильные слова для ответа на действия Вашингтона и его вольных или подневольных союзников, не опускаясь до блатной распальцовки. (Известия, 2014.04.29)

Как показано в примере (10), способом коммуникации Запада, в частности США, являются санкции, которые ассоциируются с уголовным жаргонам (ботать по фене, блатная распальиовка) и с оружием (см. раздел 4.2.1). Напротив, Россия говорит на «великом языке» («язык Толстого и Достоевского») и, следовательно, хочет найти правильные слова. Прежде всего, метафора общения употребляется в дискурсе, чтобы создать положительный образ России: несмотря на угрозу, Россия открыта к диалогу и к сотрудничеству с другими странами.

\section{5. Заключение}

В данной работе представлены результаты исследования изображения российскими СМИ санкционного процесса в его начальной фазе на основе анализа конкордансов.

В первую очередь были проанализированы прилагательные, описывающие санкции в дискурсе. Самые частотные и интересные результаты показали, что в российских СМИ выделяются различные виды санкций (экономические, финансовые и др.) и указываются их инициаторы (американские, западные и др.).

Кроме того, был проведен анализ глаголов, встречающихся в контекстах ключевого слова санкиии. Наиболее частотные глаголы выражают введение санкций (ввести, наложить и др.). Самые интересные и довольно частотные глаголы связаны с понятиями страха и угрозы. 
Проанализированные данные показали, что эти понятия помогают метафорически представить санкционную политику как войну, а санкции - как оружие. Самые частотные кластеры показывают, что Запад противник России (предлог против), которая находится под угрозой (предлог под). Кроме того, Россия предстает готовой реагировать на угрозу: в этих случаях в дискурсе используется метафора общения, для того чтобы создать образ открытой к диалогу России.

\section{Библиографический список / References}

Абрамова, Субботина, Климова, 2019 - Абрамова Е.С., Субботина И.М., Климова Ю.А. Образ Запада в зеркале российской прессы: сферы-источники метафорической экспансии // Филологические науки. Вопросы теории и практики. 2019. Вып. 2. С. 167-171. [Abramova E.S., Subbotina I.M., Klimova Yu.A. Image of the West in the mirror of the Russian press: Spheres-sources of metaphorical expansion. Filologicheskie nauki. Voprosy teorii i praktiki. 2019. No. 2. Pp. 167-171. (In Russ.)]

Баранов, 2001 - Баранов А.Н. Введение в прикладную лингвистику: Учеб. пособие. М., 2001. [Baranov A.N. Vvedenie v prikladnuyu lingvistiku [Introduction to applied linguistics]. Textbook. Moscow, 2001.]

Будаев, 2008 - Будаев Э.В. Военная метафорика в дискурсе СМИ // Acta Linguistica. 2008. Вып. 2. С. 29-36. [Budaev E.V. War metaphorics in media discourse. Acta Linguistica. 2008. No. 2. Pp. 29-36. (In Russ.)]

Ковязина, Ильющеня, Хабибуллина, 2018 - Ковязина М.А., Ильющеня Т.А., Хабибуллина С.Б. Средства выражения отрицательной оценки при описании санкционной политики западных стран в отношении России и российских ответных санкций в текстах британских сетевых СМИ: корпусное исследование // Политическая коммуникация. 2018. Вып. 2. С. 61-67. [Kovyazina M.A., Il'yushchenya T.A., Khabullina S.B. Negative evaluative language in description of anti-Russian sanctions policy and of Russian counter-sanctions in British online media discourse: A corpus-based research. Politicheskaya kommunikatsiya. 2018. No. 2. Pp. 61-67. (In Russ.)]

Кропотухина, Тихонов, 2015 - Кропотухина П.В., Тихонов В.В. Метафоры и «контрметафоры» санкционного дискурса // Политическая коммуникация. 2015. Вып. 4. С. 97-100. [Kropotukhina P.V., Tikhonov V.V. Metaphors and "counter-metaphors" of the sanctions discourse. Politicheskaya kommunikatsiya. 2015. No. 4. Pp. 97-100. (In Russ.)]

Плунгян, Рахилина, 2000 - Плунгян В.А., Рахилина Е.В. По поводу «локалистской» концепции значения: предлог под // Исследования по семантике предлогов: Сб. ст. / Под ред. Пайар Д., Селиверстовой О.Н. М., 2000. С. 115-133. [Plungyan V.A., Rakhilina E.V. On the "localist" conception of the meaning: The preposition pod. Issledovaniya po semantike predlogov. Paiar D., Seliverstova O.N. (eds.). Moscow, 2000. Pp. 115-133. (In Russ.)]

Ушаков, 2008 - Ушаков Д.Н. Большой толковый словарь русского языка. М., 2008 [Ushakov D.N. Bol'shoi tolkovyi slovar' sovremennogo russkogo yazyka [Big explanatory dictionary of the modern Russian language]. Moscow, 2008.] 
Чудинов, 2006 - Чудинов А.П. Политическая лингвистика: Учеб. пособие. M., 2006. [Chudinov A.P. Politicheskaya lingvistika [Political Linguistics]. Textbook. Moscow, 2006.]

Baker, 2006 - Baker P. Using corpora in discourse analysis. London, New York, 2006.

Charteris-Black, 2004 - Charteris-Black J. Corpus approaches to critical metaphor analysis. Basingstoke, 2004.

Croft, Cruse, 2004 - Croft W., Cruse D.A. Cognitive Linguistics. Cambridge, 2004.

Fairclough, 1989 - Fairclough N. Language and Power. London, 1989.

Kövecses, 2010 - Kövecses Z. Metaphor. A practical introduction. Oxford, 2010.

Lakoff, Johnson, 1980 - Lakoff G., Johnson M. Metaphors we live by. Chicago, 1980.

Lakoff, 2004 - Lakoff G. Don't think of an elephant! Know your values and frame the debate. White River Junction, VT, 2004.

Lakoff, 2006 - Lakoff G. Thinking Points. Communicating our American values and vision. New York, 2006.

Sinclair, 1991 - Sinclair J. Corpus, concordance, collocation. Oxford, 1991.

Sinclair, 2004 - Sinclair J. Trust the text. Language, corpus and discourse. London, 2004.

Статья поступила в редакцию 15.11.2019

The article was received on 15.11.2019

\section{Сведения об авторе / About the author}

Пинелли Эрика - научный сотрудник факультета гуманитарных наук, Павийский Университет, Италия

Erica Pinelli - Research fellow at the Department of Humanities, University of Pavia, Italy

ORCID: https://orcid.org/0000-0001-9729-1075

E-mail: erica.pinelli@unipv.it 